\title{
Genetic analysis of ecological relevant morphological variability in Plantago lanceolata L. I Population characteristics*
}

\author{
Kirsten Wolff and \\ Wilke Van Delden
}

\begin{abstract}
Department of Genetics, Centre of Biological Sciences, Kerklaan 30, 9751 NN Haren, The Netherlands.
\end{abstract}

Morphological variation in Plantago lanceolata $L$. was studied in a greenhouse and in an experimental garden, using members of full-sib families from four populations. The study included two hayfield populations and two pasture populations. The morphological differences found in the natural populations were also observed in both experiments, it was thus concluded that for most characters the variation was partly genetic. In addition to significant interpopulational genetic variation also appreciable intrapopulational genetic variation (i.e., between and within fullsib families) was observed. The population varied in amount of variation, heritability estimates, genetic correlations and in environmental sensitivity. Each population seems well adapted to its habitat. The results suggest that microevolution is retarded in some populations by unfavourable genetic correlation structures among characters under simultaneous selection, by inhomogeneous habitat characteristics or by relatively high levels of phenotypic plasticity. Selection forces responsible for the population characteristics are discussed.

\section{INTRODUCTION}

Life history and morphological studies in several plant species demonstrate the impact of selection on ecologically important characters. Venable (1984) and Bradshaw (1984) have given a review of recent studies concerning the genetic background of life history variation. Studies concerning the resource allocation in two related Plantago species ( $P$. major and $P$. rugelli) e.g., showed the existence of adaptations to the level of habitat disturbance (Hawthorn and Cavers, 1978). In the predominantly inbreeding species Plantago major it was found that each population is adapted to its specific habitat: the total genetic variability for morphological characters consisted of a large interpopulational component and a comparatively small intrapopulational component (Van Dijk, 1985; Wolff, in preparation).

There is a considerable amount of literature on ecotypic differentiation of the abundantly occurring species Plantago lanceolata (Böcher, 1943; Cavers et al., 1980; Teramura et al., 1981). Antonovics and Primack (1982) claimed that in field experiments genetic differences in life history characteristics, such as mortality and fecundity,

* Grassland Species Research Group Publication No. 110. between populations were unimportant compared to environmental influences. The study of Van Groenendael (1985), on the contrary, revealed substantial genetic differences in life history characteristics between two populations. In his reciprocal transplant experiments there was a better performance in most life stages of the genotypes in their own environment. Reciprocal transplants with other populations of $P$. lanceolata showed the same trend, though only in the adult phase (Van der Toorn et al., 1984).

Plantago lanceolata is known to be relatively plastic for a lot of morphological and physiological characters (Van der Toorn et al., 1980; Kuiper, 1984). Van Dijk (1985) suggests that phenotypic plasticity is the main mechanism by which this species copes with heterogeneous environments. Extrapolation of results from laboratory experiments to the natural habitat must be done very carefully. This is illustrated by experiments of Primack and Antonovics (1981 and 1982) on the reproductive effort of $P$. lanceolata populations under different experimental conditions. Although high heritabilities for seed yield components were found in the laboratory, environmental effects were often more important than genetic effects. 
The present study, which is the first of a series, concentrates on the genetic differentiation of some of the ecotypes of $P$. lanceolata present in the Netherlands. It was previously found that there are no consistent differences in electrophoretic variation among these ecotypes and there are no specific allele-habitat correlations (Van Dijk, 1985).

For this purpose ecologically important morphological and life history characters were studied under two uniform conditions. Using fullsib families from distinct populations it is possible to estimate the between and the within population components of variability. Genotype-environment interactions can be analysed by combining results from a greenhouse and from a garden. Comparing the amount of genetic variation within each population for each character and the presence of genetic correlations, allows inference on the selective forces which were present in the past of each populations (e.g., weak or strong directional selection or some type of balancing selection). These inferences can in turn be compared with what is to be expected from the physical conditions of the habitat. If the inferences from the heritability estimates agree with the a priori expectations, it can be concluded that the populations are, to a certain degree, adapted to their habitat.

\section{MATERIALS AND METHODS}

\section{Plants and experimental conditions}

Four populations of Plantago lanceolata $L$. were chosen on the basis of their demographic characters, electrophoretic variation and ecotypic contrasts. They included two hayfields, Heteren $(\mathrm{He})$ and Merrevliet (Me) and two extensively grazed pastures, Pannerden $(\mathrm{Pa})$ and Westduinen (Wd). In table 1 a summary of the habitat characteristics is given; for a more detailed description see Van der Toorn et al. (1980) and Van Groenendael (1985).

Seeds sampled in the four populations were sown in pots in the greenhouse. With the resulting plants several pairwise crosses were made within each population, where a particular plant was only used twice as a parent. In the Me population eight crosses were made and in the other populations six crosses, providing 26 full-sib (FS) families. The resulting seeds were germinated (April 1984) in petri-dishes on wet filter paper in the dark. Four members of each FS family were grown in the greenhouse and eight members in the common garden, both in fully randomised design. In the greenhouse the plants were kept in pots at $20-25^{\circ} \mathrm{C}$ with $16 \mathrm{~h}$ light daily. The plants destined for the garden experiment were precultured in the greenhouse in jiffypots for 3.5 weeks after germination.

In the garden there was almost no mortality (two individuals) although some Wd families were severely inhibited in growth and in flowering, presumably because of their low competitive ability. In the greenhouse three plants from $\mathrm{Pa}$ and two from a He family died in the first week. Almost all plants were flowering at the end of the experiment, i.e. after 12 and 15 weeks, for the greenhouse and the garden respectively. In the greenhouse there were two Wd plants without scapes.

\section{Characters measured}

During growth of the plants cotyledon length (at the three leaf stage) and leaf angle (angle between

Table 1 Description of the habitats of the populations used in the experiment

\begin{tabular}{|c|c|c|c|c|}
\hline Population & Soil type & Management & $\begin{array}{l}\text { Maximum height } \\
\text { of vegetation }\end{array}$ & Further details \\
\hline $\begin{array}{l}\text { Merrevliet } \\
\quad(\mathrm{Me})\end{array}$ & peat & $\begin{array}{l}\text { hayfield; mown } \\
\text { July-August }\end{array}$ & $35-40 \mathrm{~cm}$ & $\begin{array}{l}\text { a former river-bed; permanently } \\
\text { waterlogged; gradient in vegetation } \\
\text { height }\end{array}$ \\
\hline $\begin{array}{l}\text { Heteren } \\
\quad(\mathrm{He})\end{array}$ & heavy clay & $\begin{array}{l}\text { hayfield; mown end of } \\
\text { June }\end{array}$ & $42-73 \mathrm{~cm}$ & $\begin{array}{l}\text { very high and dense vegetation; high } \\
\text { biomass production; homogeneous } \\
\text { habitat }\end{array}$ \\
\hline $\begin{array}{l}\text { Pannerden } \\
\quad(\mathrm{Pa})\end{array}$ & sandy clay & $\begin{array}{l}\text { pasture; extensively } \\
\text { grazed }\end{array}$ & $12-28 \mathrm{~cm}$ & $\begin{array}{l}\text { a small river dike; moderately high and } \\
\text { dense vegetation with open spots; } \\
\text { inhomogeneous habitat }\end{array}$ \\
\hline $\begin{array}{l}\text { Westduinen } \\
\text { (Wd) }\end{array}$ & dune sand & $\begin{array}{l}\text { pasture; extensively } \\
\text { grazed }\end{array}$ & $4-7 \mathrm{~cm}$ & $\begin{array}{l}\text { old coastal grassland; short and open } \\
\text { vegetation; severe, unpredictable dryness } \\
\text { in summer }\end{array}$ \\
\hline
\end{tabular}


third and fourth leaf, at the eight leaf stage) were determined in the greenhouse only. Flowering date was recorded as the day after germination on which the first stamens were visible. Respectively twelve and fifteen weeks after germination the greenhouse and the garden plants were harvested. The following characters were measured: the number of rosettes, the number of leaves, the length of the longest leaf, the width of the widest leaf, the number of scapes, the length of the longest scape and the length of the spike belonging to this scape. The above ground biomass was separated in leaf material (leaf weight) and in scapes and spikes (generative weight). For weight determination the material was dried at $80^{\circ} \mathrm{C}$ for several days. The weight of the leaves, the generative organs and the roots (greenhouse plant only) as well as the weight of the dry seeds was determined.

From these data were calculated leaf length/ width ratio, reproductive effort measured as the ratio generative weight/leaf weight, total number of seeds (number of spikes $\times$ spike length $\times$ seeds/mm spike), total seed weight (total seed number $\times$ seed weight) and shoot/root ratio in which the shoot weight is the sum of the leaf and the generative weight (determined in the greenhouse only).

\section{Statistical and genetical analysis}

No transformation has been carried out on the data since a log transformation did not approve normality of the variables. Most calculations have been carried out using the Statistical Package for Social Sciences (SPSS) (Nie et al., 1975; Hull and Nie, 1980).

\section{Heritability estimates}

Heritability was estimated as

$$
h^{2}=2\left(\frac{s_{B}^{2}}{s_{B}^{2}+s_{W}^{2}}\right),
$$

where $s_{B}^{2}$ and $s_{W}^{2}$ are the estimates of within and between family components of variance. This gives an estimate of the narrow heritability (additive genetic variance) when dominance variation and variation due to common environment are zero (Falconer, 1982; Lawrence, 1984). In fact it estimates

$$
\frac{V_{A}+\frac{V_{D}}{2}+V_{E C}}{V_{A}+V_{D}+V_{E}+V_{E C}} .
$$

The 95 per cent confidence interval was calculated as (Stam, pers. comm.):

$$
\frac{2}{1+\frac{n F_{\alpha}}{R-F_{\alpha}}}<h^{2}<\frac{2}{1+\frac{n F_{1-\alpha}}{R-F_{1-\alpha}}}
$$

where $R=M S_{B} / M S_{W}$ and $M S_{B}$ and $M S_{W}$ stand for mean squares between and within families and $F_{\alpha}$ is the critical value of the relevant $F$-distribution.

\section{Genotype-environment interaction}

No statistical tests were carried out on the performance of the population in both environments to analyse genotype $\times$ environment interaction. The different reaction of the plants of the four populations on the differing environments was obvious. To describe the difference in reaction of the populations on the two environments (environmental sensitivity, Falconer, 1982) the following formula was used:

$$
D_{i}=100 \times\left|\frac{\bar{X}_{i 1}}{\bar{X}_{.1}}-\frac{\bar{X}_{i 2}}{\bar{X}_{.2}}\right|
$$

where $D_{i}=$ absolute difference in relative performance of population $i$ in both environments

$\bar{X}_{i 1}=$ mean performance of population $i$ in environment 1

$\bar{X}_{i 2}=$ mean performance of population $i$ in environment 2

$\bar{X}_{.1}=$ mean performance of all plants in environment 1

$\bar{X}_{.2}=$ mean performance of all plants in environment 2

In this calculation the mean performance of all plants is thus taken as the environmental value. The environmental sensitivity of the population (or the genotype) is the regression of its own value on the environmental value (Falconer, 1982).

$D_{i}$ was calculated for each character separately. The $D_{i}$ 's of the four populations were ranked from one to four for each character. Friedman's test was used to ascertain a heterogeneity in rank over characters (Sokal and Rohlf, 1981). The $D_{i}$ 's were also calculated for families within populations.

\section{Genetic correlations}

The estimation of genetic correlations rests on the resemblance between relatives in a manner 
analogous to the estimation of heritabilities (Falconer 1982). Therefore the genetic correlation is obtained as

$$
r_{A}=\frac{\operatorname{cov}_{X Y}}{\sqrt{\left(\operatorname{var}_{X} \times \operatorname{var}_{Y}\right)}}
$$

where var and cov refer to the between family components of variance and covariance of the characters $X$ and $Y$.

\section{RESULTS}

\section{Morphological characteristics}

The data of the full-sib families from the four populations, grown in the greenhouse and in the garden show considerable differentiation for morphological and life history characters. Table 2 gives the means of all families in each population and the coefficients of variation. In table 3 the significance of the differences between the populations is given. For some characters the differences are significant in one or both environments. Total seed number shows differences, but total seed weight in the greenhouse is astonishingly similar for the four populations.

All populations show properties which are characteristic for their particular habitat. The hayfield populations are characterised by long leaves, cotyledons and scapes, a small leaf angle and a high seed weight. The pasture populations have short leaves, short scapes and many small seeds. The resemblance between the two hayfield populations seems greater than between the two pasture populations. The population from $\mathrm{Wd}$ is more extreme than $\mathrm{Pa}$ in having the largest leaf angle and the shortest leaves. Wd differs from the other populations in a higher shoot/root ratio. The He plants flower earliest.

To arrange total variability clearly, a principal component analysis was applied to means of all families. It showed that in both environments all three components explain 70 per cent and 77 per cent of total variation in greenhouse and garden respectively (data not presented). The first component is interpreted as a contrast between leaf angle and leaf and scape length, providing an index for the height of the plants. The second component is interpreted as an index for vegetative biomass, a combination of number of leaves, number of rosettes and flowering data. The third component is interpreted as an index for generative biomass, especially total seed yield. The factor scores for each family are calculated and the family scores for the first two components are plotted in fig. 1 . It shows that the Wd families are separated from the others.

\section{Variation between and within populations}

The variation observed was partitioned into variation between populations, between families and

Table 2 Mean values and coefficients of variation (between brackets) of characters measured in FS families of four populations, grown in the greenhouse and in the garden. Each population consisted of 6-8 families. In the greenhouse four plants per family and in the garden eight plants per family were measured (- not measured)

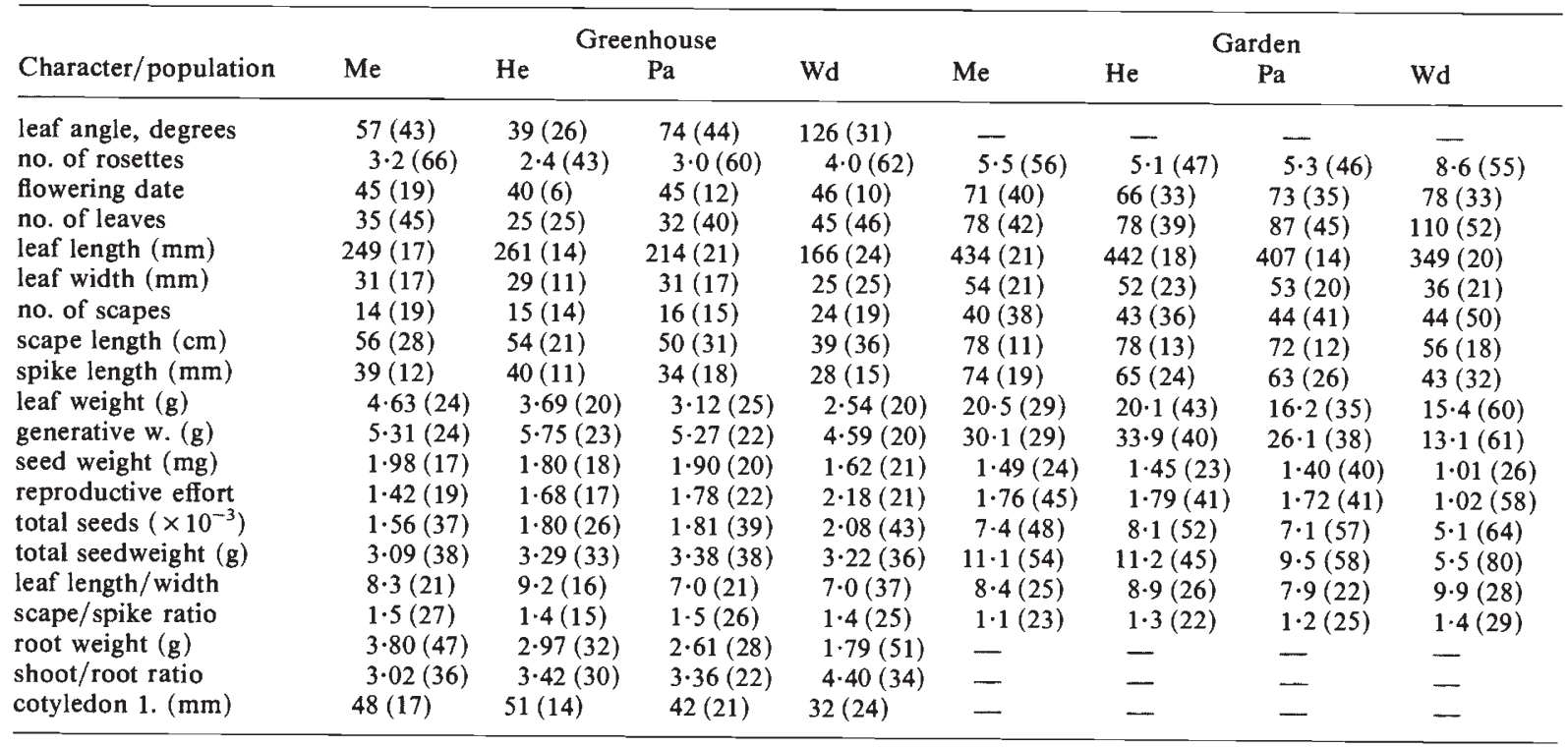


Table 3 Between population and between family variance components of variance of quantitative characters presented as percentages of total variance and calculated from variance components derived from a nested analysis of variance $\left({ }^{* * *} p<0 \cdot 001 ;{ }^{* *} p<0 \cdot 01 ;{ }^{*} p<\right.$ 0.05 ; - not measured)

\begin{tabular}{llllc}
\hline & \multicolumn{3}{c}{ Greenhouse } & \multicolumn{2}{c}{ Garden } \\
Character/factor & Population & Family & Population & Family \\
\hline leaf angle & $61^{* * *}$ & $21^{* * *}$ & - & - \\
no. of rosettes & 2 & $24^{* * *}$ & $16^{*}$ & $24^{* * *}$ \\
flowering date & 6 & $51^{* * *}$ & $13^{*}$ & $21^{* * *}$ \\
no. of leaves & $18^{*}$ & $14^{*}$ & 6 & $23^{* * *}$ \\
leaf length & $55^{* * *}$ & $15^{* * *}$ & $18^{*}$ & $26^{* * *}$ \\
leaf width & $18^{* * *}$ & $25^{* * *}$ & $39^{* * *}$ & $20^{* * *}$ \\
no. of spaces & $37^{* * *}$ & $12^{*}$ & $<0$ & $24^{* * *}$ \\
scape length & $48^{* * *}$ & $13^{* *}$ & $52^{* * *}$ & $17^{* * *}$ \\
spike length & $27^{* *}$ & $16^{* *}$ & $41^{* * *}$ & $17^{* * *}$ \\
leaf weight & $30^{* *}$ & $33^{* * *}$ & $<0$ & $43^{* * *}$ \\
generative weight & 10 & $15^{*}$ & $37^{* * *}$ & $27^{* * *}$ \\
seed weight & 11 & $15^{*}$ & $18^{* *}$ & $13^{* * *}$ \\
reproductive effort & 11 & $26^{* *}$ & $16^{*}$ & $25^{* * *}$ \\
leaf length/width & $18^{*}$ & $38^{* * *}$ & $11^{*}$ & $21^{* * *}$ \\
root weight & 28 & $35^{* * *}$ & - & - \\
shoot/root ratio & $13^{*}$ & $18^{*}$ & - & - \\
cotyledon length & $55^{* * *}$ & $16^{* * *}$ & - & - \\
\hline
\end{tabular}

within families (table 3). It appears that substantial variation is present both within and between populations. The within family variability cannot be split up further with this experimental setup.

The variability within each population is expressed as the coefficient of variation (CV). The $\mathrm{CV}$ enables comparisons of differences between characters. Leaf length, leaf width, cotyledon length and scape length have a relatively low CV within populations. The coefficients of variation for all characters were ranked one to four for the four populations: there was inconsistency in variability over populations (significance of Friedman's test: $p<0.0005)$. The He population has the lowest score for mean coefficients of variation and $\mathrm{Wd}$ the highest when all characters are taken into account.

Partitioning of variation within each population separately into variation within and between families gives for Wd in the greenhouse a high within family component of variation, this partly causes the high CV (data not presented).

\section{Heritability estimates}

From the analysis of variance of the full-sib (FS) families within each population the heritability of each character was estimated (table 4). The heritability estimates are upper limits since the dominance variation and the common environment component are included in the estimate of $V_{A}$. The heritability estimates have large confidence inter- vals due to the small number of families and to a lesser extent, to the small family size. For most characters genetic variation is present in each population though the $h^{2}$ values show great variation over populations and environments.

\section{Correlation}

The phenotypic correlations were partitioned into environmental correlations, genetic correlations and correlations between population means. The partitioning of these correlations is a necessity as appeared later.

Environmental (within families) correlations are among others caused by morphogenetic processes. The figures show e.g., that late flowering is associated with many long leaves, a high leaf and root weight and thus with a low reproductive effort. The correlation between seeds/mm spike and seed weight is negative $(-0.42$ in the greenhouse and $-0 \cdot 19$ in the garden).

Genetic correlations were calculated as described in materials and methods. The standard errors, calculated according to Falconer (1982), were very large, so the figures are only indicative of a possible positive or negative correlation. For $\mathrm{He}$ and Me genetic correlations found in the garden experiment and for $\mathrm{Pa}$ and $\mathrm{Wd}$ those for the greenhouse experiment are discussed as these experimental conditions seem most relevant for the natural situation in which these plants occur. 


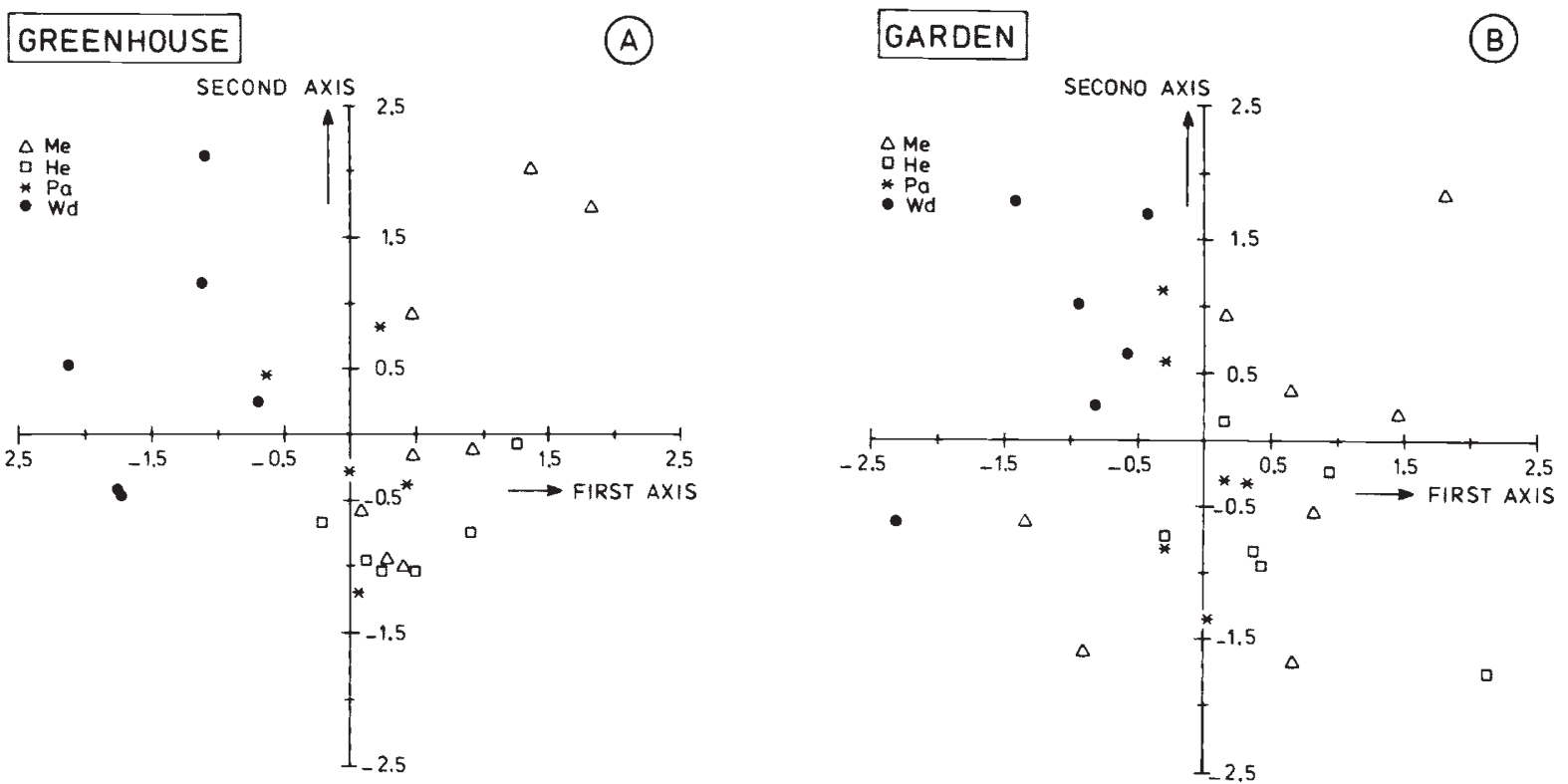

Figure 1 Factor scores of the families of the four populations on the first axes derived from a principal component analysis of the means of all families. (a) in the greenhouse, (b) in the garden. $\square \mathrm{He}, \triangle \mathrm{Me},{ }^{*} \mathrm{~Pa}, \bigcirc \mathrm{Wd}$.

Comparing the genetic correlation structures of the two hayfield populations in the garden experiment (table 5) shows some interesting phenomena. The correlations shown in the table are a subset of the total set of traits measured for reasons of clearness. The correlations in the $\mathrm{He}$ population are nearly all positive, except for the correlations with flowering date. This means that early flowering plants have optimal hayfield traits: long leaves, scape and spikes with many heavy seeds. The Me population shows less strong correlations of which several are not in the favourable direction, e.g. negative correlations between scape length and spike length and between spike length and seed weight.

Comparing $\mathrm{Pa}$ and $\mathrm{Wd}$ (data not presented) shows contradicting correlations: in $\mathrm{Pa}$ a large leaf angle combines with many short leaves and a low

Table 4 Heritability estimates calculated from FS families in the four populations. Heritabilities significantly different from zero $(p<0 \cdot 05)$ are indicated by $*(-$ not measured $)$

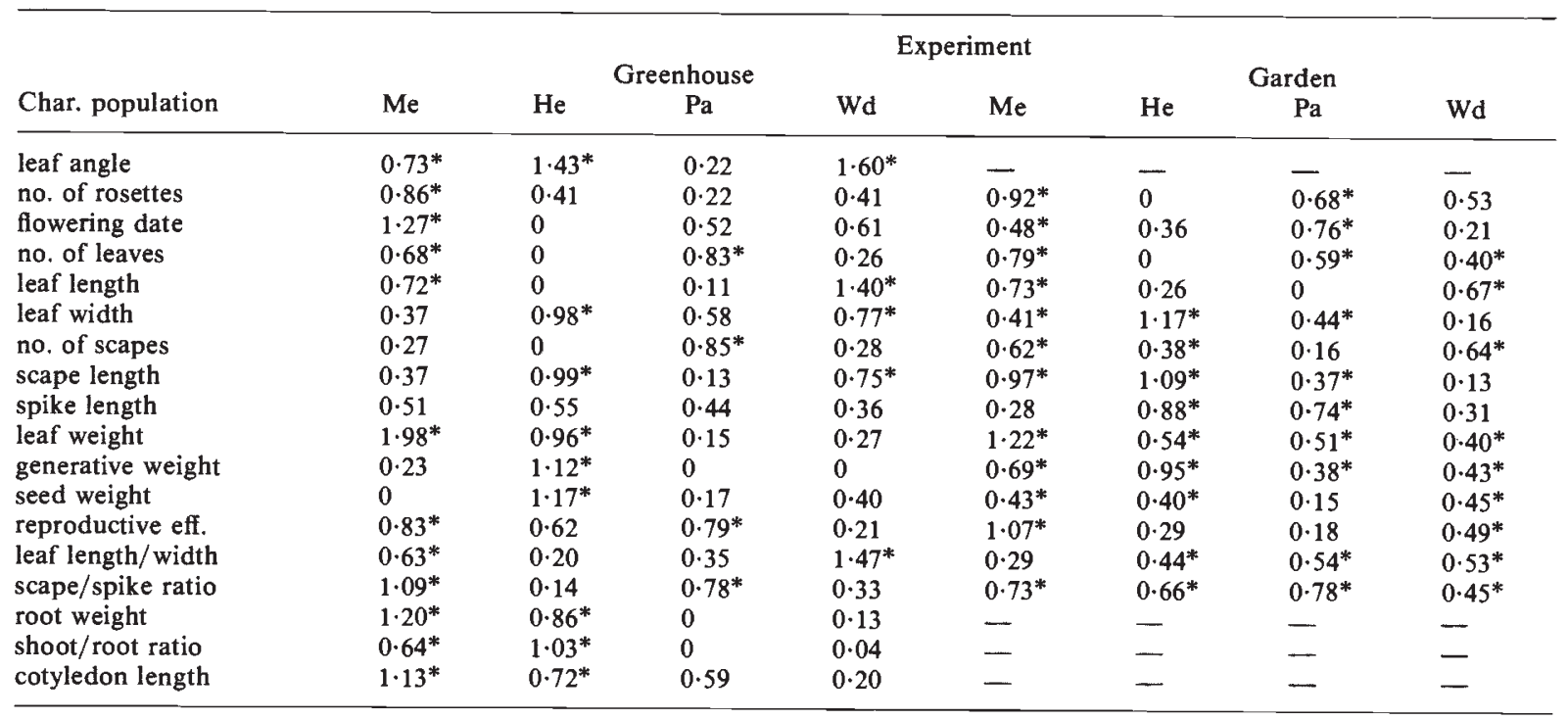


Table 5 Genetic correlations between a number of characters of the populations He and Me; upper triangle He population and lower triangle Me population (garden experiment)

\begin{tabular}{|c|c|c|c|c|c|c|c|c|c|c|c|c|}
\hline \multicolumn{2}{|c|}{ Character } & \multirow[t]{2}{*}{1} & \multirow{2}{*}{$\frac{2}{-0.73}$} & \multirow{2}{*}{$\frac{3}{-0.75}$} & \multirow{2}{*}{$\frac{4}{-0.20}$} & \multirow{2}{*}{$\begin{array}{l}5 \\
-0.39\end{array}$} & \multirow{2}{*}{$\frac{6}{-0.43}$} & \multirow{2}{*}{$\frac{7}{-0.39}$} & \multirow{2}{*}{$\frac{8}{-0.74}$} & \multirow{2}{*}{$\frac{9}{+0.11}$} & \multirow{2}{*}{$\frac{10}{-0.19}$} & \multirow{2}{*}{$\frac{11}{-0.41}$} \\
\hline 1 & flowering date & & & & & & & & & & & \\
\hline 2 & leaf length & $+0 \cdot 48$ & & +0.74 & +0.68 & +0.67 & +0.90 & +0.76 & +0.54 & $-0 \cdot 10$ & +0.75 & -0.91 \\
\hline 4 & scape length & +0.44 & $+0 \cdot 86$ & -0.05 & & +0.51 & +0.78 & +0.92 & +0.53 & +0.51 & +0.52 & +0.72 \\
\hline 5 & spike length & +0.08 & $-0 \cdot 34$ & $-0 \cdot 30$ & -0.53 & & +0.58 & +0.53 & $+0 \cdot 20$ & $+0 \cdot 11$ & +0.71 & +0.73 \\
\hline 6 & leaf weight & +0.94 & +0.63 & +0.04 & +0.53 & +0.07 & & $+0 \cdot 87$ & +0.37 & -0.01 & +0.79 & +0.91 \\
\hline 9 & reproductive eff. & -0.89 & -0.44 & $-0 \cdot 12$ & $-0 \cdot 20$ & $-0 \cdot 18$ & -0.91 & $-0 \cdot 16$ & -0.45 & & -0.36 & $-0 \cdot 17$ \\
\hline 10 & total seeds & -0.29 & $-0 \cdot 24$ & +0.47 & $+0 \cdot 16$ & +0.22 & $-0 \cdot 22$ & +0.09 & -0.22 & -0.02 & & +0.94 \\
\hline 11 & total seed weight & $-0 \cdot 35$ & +0.02 & +0.57 & $-0 \cdot 26$ & $-0 \cdot 13$ & $-0 \cdot 20$ & +0.43 & +0.26 & $-0 \cdot 13$ & +0.86 & \\
\hline
\end{tabular}

reproductive effort, whereas in Wd the high leaf angle combines with a low number of short leaves and a high reproductive effort.

The correlation between population character means (data not presented) shows the contrast between the two ecotypes, as was also found using a principal component analysis. A large leaf angle is associated with late flowering, many, short leaves, short scapes and many seeds.

\section{Genotype-environment interaction}

Some conclusions can be drawn for the genotypeenvironment interaction by comparing the mean sensitivity of the populations (calculated from table 2 as described before, data not presented). This means that a population with a lower environmental sensitivity $\left(D_{i}\right)$ (over all characters) than the other populations is less sensitive for environmental changes than populations with a higher overall $D_{i}$. Friedmann's test shows a significant heterogenity in rank of $D_{i}$ between the populations $(p<0.005)$. It shows that $\mathrm{Pa}$ has the lowest $G \times E$ interaction and $\mathrm{Wd}$ the highest. This means that $\mathrm{Pa}$ is least influenced by the environment while Wd is most affected and Me and He take an intermediate position. By measuring the sensitivity of families within populations using the same method, it turned out that there is variability for sensitivity within each population (data not presented).

\section{DISCUSSION}

\section{Ecotype differentiation}

The results of the experiments in the greenhouse and in the garden show that the degree of differentiation between the four populations is in good agreement with the ecological needs in the respective habitats. The hayfield populations show characteristics typical for this habitat. The low light transmission in the high vegetation (Slim and Van der Toorn, 1983) causes a high competition for light. Plants with long cotyledons have better chances of surviving the first phase of life and only adult plants with long leaves, small leaf angle and long scapes, to capture and disperse the pollen above the vegetation, are reproductively successful. The pasture populations show traits adapted to a more open habitat with higher light transmission (Slim and Van der Toorn, 1983). Prostrate leaves and scapes have a lower risk of being grazed. Dividing biomass over many leaves and many scapes spreads the risk. This is, among others, achieved by forming many side rosettes; plants with a large leaf angle, with many small leaves and many small scapes are favoured in this habitat. These specific characteristics are more pronounced in Wd than in $\mathrm{Pa}$. The habitat of the Pa population tends to a ruderal site with a higher vegetation, compared to $\mathrm{Wd}$, and $\mathrm{Pa}$ consequently has mixed characteristics.

The He population flowered earlier than the others; this points at selection for early flowering in this early mown hayfield. It thus appears that the differences have a genetical background, as was suggested by the experiments of Van der Toorn et al. (1980) and Van Groenendael (1985).

In general it appears that in $P$. lanceolata, with its rather plastic phenotype, the phenotypic differences found in the field coincide with differences found in experiments under controlled conditions (Van Groenendael, 1985 and Slim and Van der Toorn, 1983). This is stressed by the good correlation between the factor score of the families on the first three principal components (greenhouse results) with different fitness characters in the garden (table 6). The possibility to predict the 
Table 6 Correlations between factor scores of family means, as calculated from a principal component analysis on the greenhouse results, with family means of several characters in the garden (only significant correlations are given: $\left.{ }^{* * *} p<0.001,{ }^{* *} p<0.01, * p<0.05\right)$

\begin{tabular}{llll}
\hline Character score & PCA1 $^{\$}$ & PCA2 $^{\$}$ & PCA3 $^{\$}$ \\
\hline no. of rosettes & - & $+0.67^{* * *}$ & - \\
flowering date & - & $+0.71^{* * *}$ & - \\
no. of leaves & - & $+0.61^{* * *}$ & - \\
leaf length & $+0.66^{* * *}$ & - & $-0.40^{*}$ \\
leaf width & $+0.69^{* * *}$ & - & - \\
no. of scapes & - & - & - \\
scape length & $+0.86^{* * *}$ & - & - \\
spike length & $+0.71^{* * *}$ & - & - \\
leaf weight & $+0.51^{* * *}$ & $+0.42^{*}$ & $-0.42^{*}$ \\
generative weight & $+0.73^{* * *}$ & - & - \\
seed weight & $+0.68^{* * *}$ & - & - \\
reproductive effort & $+0.42^{* * *}$ & $-0.58^{* *}$ & - \\
total seeds & $+0.43^{*}$ & - & - \\
total seed weight & $+0.62^{* * *}$ & - & -
\end{tabular}

$\$$ the interpretations of the axes were: PCA1: height of the plants, PCA2: vegetative growth, PCA3: generative growth.

performance of plants in a specific environment from results in a controlled environment was also shown by Van Groenendael (1985), correlating factor scores from the greenhouse with results in the field.

The rather uniform seed output (expressed as weight per plant) as found here was also found by Primack and Antonovics (1981). It is achieved either by many spikes with small seeds, as in Wd, or a few long spikes with heavy seeds, as in $\mathrm{He}$ and $\mathrm{Me}$. This phenomenon suggests that selection forces operating on seed biomass can be bidirectional; many small seeds or fewer but heavy seeds. In general it can be posed that selection will be towards many seeds since this will give a spread of seed material in time and in space: a necessity in Westduinen with its unpredictable droughts. The importance of a high reproductive effort in Westduinen is shown in the models of Van Groenendael (1985). The counterforce, which is stronger in populations $\mathrm{Me}$ and $\mathrm{He}$, is to produce seeds big enough to provide seedlings with long cotyledons as a strong positive correlation between seed size and cotyledon length is found (Van Groenendael, 1985).

\section{Variability, heritability and correlations}

The amount of morphological variability present in a population is the result of several interconnected factors. The mating system, the plasticity of characters and selective forces in the past all exert influences on phenotypic variation. The distribution of the total variation over within family and between family variation sheds some light on these factors. A low level of variability between families within a population may point either at strong selection in the past for that character in only one direction or a small genetic component of variability.

Tables 2 and 3 show that variation, on which selection may act, is to a great extent available in all populations for most characters, although in He lower CV's and lower heritabilities are found. Since a normal level of allozyme variation is present in He (Van Dijk, 1985) the low heritabilities found here are not caused by drift or a bottleneck. The low heritabilities may witness strong selection in the past for these characters.

The heritabilities found in the populations are in good agreement with those found for other species (Venable, 1984; Bradshaw, 1984) and from other experiments with Plantago lanceolata (Primack and Antonovics, 1981).

The difference between $P$. lanceolata and $P$. major, with respect to the presence and distribution of genetic variation, resembles the often observed difference between inbreeding and outbreeding species (Hamrick et al., 1978; Van Dijk, 1984; Wolff, in prep.). In $P$. major almost all variation is between ecotypes and between the two subspecies: major and pleiosperma. The variation within families is lost by selfing and the variation within the population is lost by selection between selfed progenies. In $P$. lanceolata a great amount of variation is evident within families and within and between populations. Variation is preserved by obligate outcrossing, considerable gene flow (Bos et al., 1986) and the occupation of many types of habitats with contrasting selection regimes.

Between family correlations indicate the existence of genetic correlations. The existence of genetic correlations was also found in an experiment in which quantitative trait loci were localised using allozyme markers (Wolff, in prep.). In $\mathrm{He}$ strong selection for typical hayfield traits has caused loss of a great part of variability: genetic correlations did not prevent this. In Me the plants with hayfield characteristics (long leaves and heavy seeds) have a low reproductive effort and few seeds, which means a low contribution of the better hayfield types to the next generation. So here exists an unfavourable genetic correlation structure. Differences in genetic correlations between populations are also described by Silander (1985) for Spartina pratens. For this species it was hypothesised that further microevolution was retarded in some populations by unfavourable genetic correlation structures. Results of this 
experiment suggest that also for Plantago lanceolata selection will lower the variability (as in $\mathrm{He}$ ) unless correlated characters prevent this (as in $\mathrm{Me}$, $\mathrm{Pa}$ and $\mathrm{Wd}$ ).

\section{Description and comparison of the populations}

Combining the data on levels of variation, heritabilities, sensitivity of characters and habitat characteristics, enables a description of a possible historical background of the populations. The He population shows low variability for many characters. It leads to the conclusion that strong directional selection in this, apparently highly homogenous habitat leads to the exhaustion of the genetic variability for particular characters. The positive and negative correlations between the hayfield characteristics and flowering date do not prevent this. The other hayfield population (Me) comes from a more variable habitat where in the marginal areas less extreme hayfield types will survive. This field is mown later in the season giving a high variability for flowering date. Habitat variability, negative correlations between fitness characters, together with selection give rise to typical hayfield characteristics associated with high heritabilities and intermediate stability of genotypes.

The Pa population has an exceptional low sensitivity of rharacters over both environments. This can be explained from its stable but inhomogeneous habitat and from the choice of the two experimental conditions, both fitting in the natural habitat of $\mathrm{Pa}$. In this habitat there are patches which are grazed regularly and patches with a higher vegetation with less attractive plant species. Selection is not unidirectional over the whole population, although on the average it tends to an intermediate pasture type. The Wd population comes from a habitat which is rather harsh. The soil has a rather low nutrient availability (Van Groenendael, 1985), especially in dry periods in the summer. The dryness is unpredictable and causes a high mortality (Van Damme and Van Delden, 1984). Grazing causes great losses of vegetative and generative biomass. Good perspectives for survival and seed setting are only present in good (wet) years or in patches with a better microclimate: around small ponds or cattle excrements. Selection has put a premium on the more sensitive genotypes possessing the possibility to expand vegetatively and reproductively when allowed by the microhabitat. The microhabitat differences, associated with possibly different genetic correlations, induce balancing selection through which variation is maintained (Giesel et al., 1982). This leads to a high level of variation and a high environmental sensitivity of the phenotype. Strong directional selection further leads to a pasture type with high leaf angle, short leaves and scapes and many but small seeds.

\section{Plasticity versus competitive ability; different strategies?}

The Wd population has the highest reproductive effort in the greenhouse, although it starts flowering later than the other populations. Primack and Antonovics (1982) describe similar behaviour for a population from an open habitat, though in their experiment the population was also capable of flowering very early in order to profit as much as possible from good conditions. Experiments with Avena barbata showed that genotypes from occasional xeric habitats were also capable of a highly plastic response to better environments (Hamrick and Allard, 1975). Werner (1985) suggests that this effect, which she also found in two Solidago species, is based on a trade-off between plasticity and competitive ability: the xeric species possesses a wide potential niche but, by the low competitive ability this results in a narrow realised niche. The high reproductive effort of the $\mathrm{Wd}$ population might indicate that this population tends more to an $r$-strategy than the $\mathrm{He}$ and $\mathrm{Me}$ populations do (Gadgil and Solbrig, 1972), which is also indicated by the correlations found between population mean characters.

Van Groenendael (1985), working with cloned material of $\mathrm{Me}$ and Wd plants, showed higher variance ratios (between-/within-genotypes) for Me plants compared to Wd plants, with the Wd plants having higher coefficients of variation. This is in agreement with the higher within family variances found here for the Wd families.

In our study it has been shown that the phenotypic variation, as measured in the field, has a large genetic component and that selection has acted on this variation leading to different genotypes. The selection together with the influence of the environment results in an array of phenotypes in each population, each adapted to its environment. These populations of Plantago lanceolata, with their genetic differences, seem appropriate for further genetic analysis of morphological variability.

Acknowledgements We wish to thank Drs M. Bos, C. Kik, P. Stam, J. Van Damme and P. Van Tienderen for their comments 
on the manuscript, Dr $\mathrm{C}$. Lewis for statistical advice and $\mathrm{P}$. Dubbeldam for technical assistance. Fig. 1 was drawn by $\mathrm{H}$. Mulder.

These investigations were supported by the Foundation for Fundamental Biological Research (BION), which is subsidised by the Netherlands Organization for the Advancement of Pure Research (ZWO).

\section{REFERENCES}

ANTONOVICS, J. AND PRIMACK, R. B. 1982. Experimental ecological genetics in Plantago VI. The demography of seedling transplants in Plantago lanceolata. J. of Ecology, 70, 55-75.

BÖCHER, T. W. 1943. Studies on variation and biology in Plan. tago lanceolata L. Dansk Bot. Archiv, 11, 1-18.

BOS, M., HARMENS, H. AND VRIELING, K. 1986. Gene flow in Plantago I Gene flow and neighbourhood size in Plantago lanceolata. Heredity, 56, 43-54.

BRADSHAW, A. D. 1984. The importance of evolutionary ideas in ecology- and vice versa. In Shorrocks, B. (ed.) Evolutionary Ecology, Blackwell, Oxford.

CAVERS, P. B., BASSETT, I. J. AND CROMPTON, C. S. 1980. The biology of Canadian weeds, 47. Plantago lanceolata L. Can. J. Plant Sci., 60, 1269-1282.

FALCONER, D. S. 1982. Introduction to Quantitative Genetics. Oliver and Boyd, Edinburgh.

GADGIL, M. AND SOLBRIG, O. T. 1972. The concept of $r$ - and $K$-selection: evidence from wild flowers and some theoretical considerations. Am. Nat., 106, 14-31.

GIESEL, J. T., MURPHY, P. AND MANLOVE, M. 1982. An investigation of the effects of temperature on the genetic organization of life historie indices in three populations of Drosophila melanogaster. In Dingle and Hegmann (eds.) Evolution and Genetics of Life Histories, Springer-Verlag, Heidelberg, Berlin.

HAMRICK, J. L. AND ALLARD, R. W. 1975. Correlations between quantitative characters and enzyme genotypes in Avena barbata. Evolution, 29, 438-442.

HAMRICK, J. L., LINHART, Y. B. AND MITTON, J. B. 1979. Relationships between life history characteristics and electrophoretically detectable genetic variation in plants. Ann. Rev. Ecol. Syst., 10, 173-200.

HAWTHORN, W. R. AND CAVERS, P. B. 1978. Resource allocation in young plants of two perennial species of Plantago. Can. J. Bot., 56, 2533-2537.

HULL, C. H. AND NIE, N. H. 1981. SPSS Update 7-9: New procedures and facilities for Releases 7-9, McGraw Hill, New York.

KUIPER, D. 1984. Genetic differentiation and phenotypic plasticity in Plantago species. Ph.D. Thesis, University of Groningen.
LAWRENCE, M. J. 1984. The genetical analysis of ecological traits. In Shorrocks, B., (ed.) Evolutionary Ecology, Blackwell, Oxford.

NIE, N. H., HULL, C. H., JENKINS, J. G., STEINBRENNER, K. AND BENT, D. H. 1970. SPSS: Statistical Package for the Social Sciences, McGraw Hill, New York.

PRIMACK, R. B. AND ANTONOVICS, J. 1981. Experimental ecological genetics in Plantago V Components of seed yield in the ribworth Plantain Plantago lanceolata L. Evolution, $35,1069-1079$.

PRIMACK, R. B. AND ANTONOVICS, J. 1982. Experimental ecological genetics in Plantago VII Reproductive effort in populations of Plantago lanceolata L. Evolution, 36, 742752.

SILANDER, J. A. 1985. The genetic basis of the ecological amplitude of Spartina pratens II Variance and correlation analysis. Evolution, 39, 1034-1052.

SLIM, P. AND VAN DER TOORN, J. 1983. Variability in morphological characters of Plantago lanceolata. Proc. Kon. Ned. Akad. Wet. Afd. Natuurk., Tweede reeks, 81, 36-41.

SOKAL, R. R. AND ROHLF, F. J. 1981. Biometry, W. H. Freemann and Co., San Francisco.

TERAMURA, A. H., ANTONOVICS, J. AND STRAIN, B. R. 1981. Experimental ecological genetics in Plantago IV Effects of temperature on growth rates and reproduction in three populations of Plantago lanceolata L. (Plantaginaceae). Amer. J. Bot., 68, 425-434.

VAN DAMME, J. M. M. AND VAN DELDEN, W. 1984. Gynodioecy in Plantago lanceolata $L$. IV Fitness components of sex type in different life cycle stages. Evolution, 38, 1326-1336.

VAN DIJK, H. 1985. Genetic variability in Plantago species in relation to their ecology. Ph.D. Thesis, University of Groningen.

VAN GROENENDAEL, J. 1985. Selection for different life histories in Plantago lanceolata. Ph.D. Thesis, University of Nijmegen.

VAN DER TOORN, J., HAECK, J. AND MOOK, J. H. 1980. Some remarks on the demography of Plantago species. Proc. Kon. Ned. Akad. v. Wetensch., Afd. Nat. Tweede reeks, 75, 16-19.

VENABLE, D. L. 1984. Using intraspecific variation to study the ecological significance and evolution of plant life-histories. In Dirzo and Sarukhan (eds.) Perspectives on Plant Population Ecology, Sunderland, Mass.

WERNER, P. A. 1985. Phenotypic variation and implications for reproductive success. In Woldendorp, J. and Haeck, J. (eds.) Structure and Functioning of Plant Populations, North Holland, Amsterdam.

WOLFF, K. 1987. Genetic analysis of ecological relevant morphological variability in Plantago lanceoalata $L$. II Localisation of quantitative trait loci. Theor. Appl. Genet. (in press).

WOLFF, K. (in prep). A comparison of morphological variability, electrophoretic variability and outcrossing rate within and between three Plantago species. 